\title{
Prediction of External Exposure during Dismantling of Steam Generator
}

\author{
Martin Hornáček, Vladimír Nečas \\ Institute of Nuclear and Physical Engineering, Slovak University of Technology in Bratislava, Slovakia \\ Email: martin.hornacek@stuba.sk, vladimir.necas@stuba.sk
}

Received 12 August 2015; accepted 15 October 2015; published 22 October 2015

\begin{abstract}
The decommissioning of nuclear power plants is in the Slovak Republic an actual issue. In 2015 started the second decommissioning stage of nuclear power plant V1 in Jaslovské Bohunice. This stage involves the dismantling and segmentation of activated (reactor pressure vessel, reactor internals) and contaminated parts (steam generators, pressurizer). From this reason it is necessary to investigate the radiation situation in the vicinity of the component to be cut. The presented results show that during remote dismantling the exposure is small (compared with the fragmentation tasks). Moreover, when the pre-dismantling decontamination with decontamination factor of 100 is applied, the total collective effective dose is below the yearly limit of $20 \mathrm{mSv}$ for workers.
\end{abstract}

\section{Keywords}

Steam Generator, Dismantling and Fragmentation, External Exposure

\section{Introduction}

During decommissioning of nuclear power plants (NPP) several steps have to be carried out in order to achieve the desired end state in the planned time schedule. This includes mainly preparation for dismantling, dismantling of technological equipment, treatment and conditioning of resulting waste, storage and the final disposal of radioactive waste and in many cases also the decontamination. It is obvious that during these activities, the proper knowledge of the radiation situation and thus the optimization of radiation protection within the ALARA principle is crucial (this principle means that the exposure, the number of exposed persons and the probability of exposure should be "As Low As Reasonably Achievable").

In case of so-called large components (e.g. activated parts-reactor pressure vessel and internals; contaminated parts-pressurizer, steam generator-SG) the usual dismantling and transportation techniques have to be modified and many factors like site-specific conditions, availability of technical tools, the strategy of radioactive waste disposal have to be taken into account [1].

In the Slovak Republic, the NPP V1 in Jaslovské Bohunice is currently in the $2^{\text {nd }}$ and final decommissioning stage with planned duration between 2015-2025 [2]. In this NPP, the VVER-440/230 reactor type (Russian type of pressurized water reactor) was used. Each unit had gross electrical output of $440 \mathrm{MW}$ and the cessation of operation was after 28 years of standard operation (1978-2006 and 1980-2008). 
Within the second decommissioning stage, the large components will be cut in-situ and the fragmented parts will be stored and/or conditioned and disposed in the repository [3].

\section{Technical Description of Steam Generator Used in NPPs with VVER-440 Type Reactor}

The subject of the analysis in this paper is the steam generator used in each of the 6 loops of the primary circuit within one unit-Figure 1.

From the construction point of view the vessel is made of carbon steel $22 \mathrm{~K}$; the collector material as well as the heat exchanging tube material is titanium stabilized austenitic steel with $0.08 \%$ carbon, $18 \%$ chromium, $10 \%$ nickel and less than $1 \%$ titanium [5].

\section{Calculation Tool VISIPLAN 3D ALARA}

The calculation of external exposure during dismantling and fragmentation of the SG was realized using code VISIPLAN 3D ALARA developed by Belgian company SCK-CEN. The photon fluency rate at the dose point near the volume source can be determined by considering the volume source as consisting of a number of point sources. By adding the contribution of every point source to the dose at the dose point the photon fluency rate at the dose point is expressed as [6]:

$$
\varphi=\int_{V} \frac{S \cdot B \cdot \mathrm{e}^{-b}}{4 \pi \rho^{2}} \mathrm{~d} V\left(m^{-2} \cdot \mathrm{s}^{-1}\right)
$$

where: $S$ - source strength per unit volume $\left(\mathrm{n} \cdot \mathrm{s}^{-1}\right)$,

$\rho$-distance from a point source $(\mathrm{m})$,

$B$-buildup coefficient (-),

$b$-attenuation effectiveness coefficient (-),

$V$-volume $\left(\mathrm{m}^{3}\right)$.

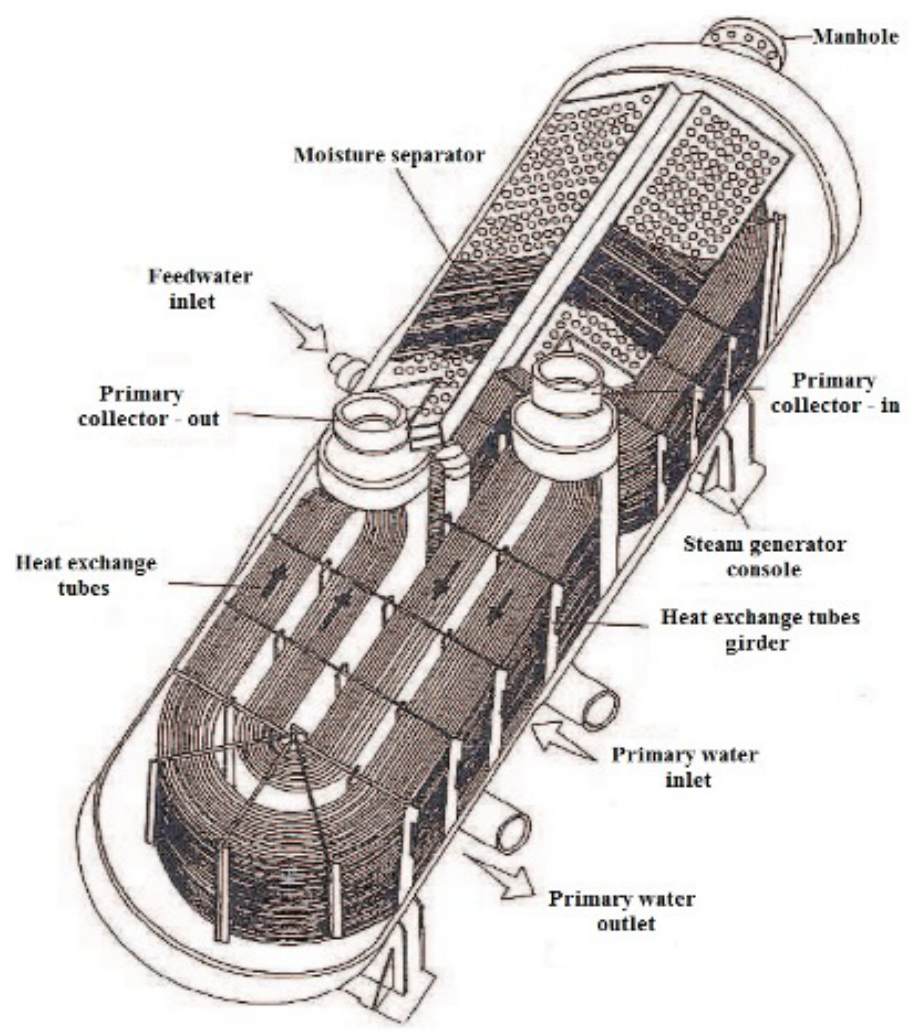

Figure 1. Steam generator for NPPs with VVER-440 type reactor [4]. 
Each small source is called a kernel and the process of integration, where the contribution to the dose of each point is added up, is called "point kernel" integration. This is the method used in the VISIPLAN software [6]. Based on the photon fluency rate at a point it is possible to calculate the effective dose rate depending on the dose conversion factors selected in the calculations [6]:

$$
E=\sum_{i} h_{i} \cdot \phi_{i}(\mathrm{~Sv} / \mathrm{s})
$$

where: $h_{i}$-dose conversion coefficient for photons of energy (Sv per photon $/ \mathrm{m}^{2}$ ), $\phi_{i}$-fluency rate of the photons at energy $\left(\mathrm{m}^{-2} \cdot \mathrm{s}^{-1}\right)$.

\section{General Preconditions and Input Data}

The chapter deals with the model of steam generator, considered input data for the calculations and considered worker group.

\subsection{Model of Steam Generator}

The considered model of steam generator consists of the following parts:

- SG casing - consisting of cylindrical part (length approx. $9.5 \mathrm{~m}$ ) and two semi-spherical parts (radius approx. $1.7 \mathrm{~m}$ ), total mass $113.4 \mathrm{t}$, part of secondary circuit—negligible level of activity.

- Heat exchange tubes (5536 pieces of U-tubes—modelled in simplified geometry), the length approx. $9.7 \mathrm{~m}$, total mass approx. $34.7 \mathrm{t}$, part of primary circuit—contaminated parts.

- 2 collectors - the height of each $4.2 \mathrm{~m}$, outer diameter $0.97 \mathrm{~m}$, the mass of $12.7 \mathrm{t}$ each, part of primary circuit—contaminated parts.

The total mass of SG is then approx. $173 \mathrm{t}$.

The steam generator is placed in so-called hermetic box made of concrete walls with thickness of $1 \mathrm{~m}$. The distance between the reactor floor and SG's axis is $7.4 \mathrm{~m}$; the distance between casing and walls is $1.7 \mathrm{~m}$.

\subsection{The Source Term}

Among the geometric dimensions and material composition the other crucial input parameter is the source term, i.e. the level of activity of each part and the nuclide composition of the source (nuclide vector). The activity content of each contaminated part of SG represents estimated values for calculation of decommissioning parameters and is depicted in Table 1.

It is necessary to emphasize that the activity values depicted in Table $\mathbf{1}$ are without applying decontamination.

The nuclide vector is derived from the radiological characterization and the most dominant nuclide is ${ }^{60} \mathrm{Co}$ with approx. 90\% share (when considering $\gamma$ and X-ray emitting nuclides)-result of standard operation with no leakages of the primary circuit.

\subsection{Worker Group}

During the cutting of steam generator and lifting the segmented parts from the hermetic box to the reactor floor, only one trajectory (set of points where the dose rate is calculated) is considered. In case of fragmentation of the segmented parts, the following worker group is considered:

- Cutter and junior technician—realization of cutting activities—-the distance from the component is $30 \mathrm{~cm}$, the time coefficient (considering the time of stay during each activity) is 1.

Table 1. Considered activity values for parts of steam generator.

\begin{tabular}{|c|c|c|c|}
\hline \multirow{2}{*}{ Component } & \multicolumn{3}{|c|}{ Activity of $\gamma$ and $X$-ray emitting nuclides [Bq] } \\
\hline & 2015 & 2020 & 2025 \\
\hline Heat exchange tubes & $19.2 \mathrm{E}+10$ & $10.7 \mathrm{E}+10$ & $6.32 \mathrm{E}+10$ \\
\hline 1 Collector & $18.6 \mathrm{E}+07$ & $10.4 \mathrm{E}+07$ & $6.15 \mathrm{E}+07$ \\
\hline
\end{tabular}


- Master and technician — management of workers, control of exposure time (master), control of the cutting techniques, the quality and speed of the cut (technician) - the distance from the component is $100 \mathrm{~cm}$, the time coefficient is 0.8 .

- Radiation protection technician-monitoring radiological situation, measurement of dose rate-the distance from the component is $100 \mathrm{~cm}$, the time coefficient is 0.3 .

\section{Considered Dismantling Procedure}

The dismantling of steam generator is considered to be realized in the hermetic box (remote dismantling with control on the reactor floor). The dismantled parts will be lifted to the reactor floor where their fragmentation will be carried out. The whole procedure is described below (in case of remote dismantling the blue person are depicted, in case of fragmentation activities the trajectory of cutter and junior technician is depicted by red persons, the other trajectories are depicted by the green persons).

In order to avoid aerosol production, the cutting using band saw is considered. The duration of each step was derived from the cutting speed of the facility for fragmentation of large components in the Interim Storage North at the Greifswald site, which varies from 15 to $80 \mathrm{~mm} / \mathrm{min}$ [7]. Within the conservative approach and since the procedure is performed in the controlled area, the lowest speed from the interval was chosen. The issue of cutting duration was also discussed with professionals [8]. Based on these data (using the time coefficients described in Chapter 4.3 as well) the time of duration of each activity and also the time of stay of each worker can be obtained.

\section{1) Dismantling activities}

- Cutting the end part of steam generator-total workload 35 man-hours (Figure 2). The hole in the reactor floor is depicted as blue rectangle.

- Lifting the fragmented part (Figure 3) - total workload of 1 man-hour. This value was derived from the considered lifting speed of $5 \mathrm{~mm} / \mathrm{s}$ and the distance from the reactor floor (approx. $9 \mathrm{~m}$ ).

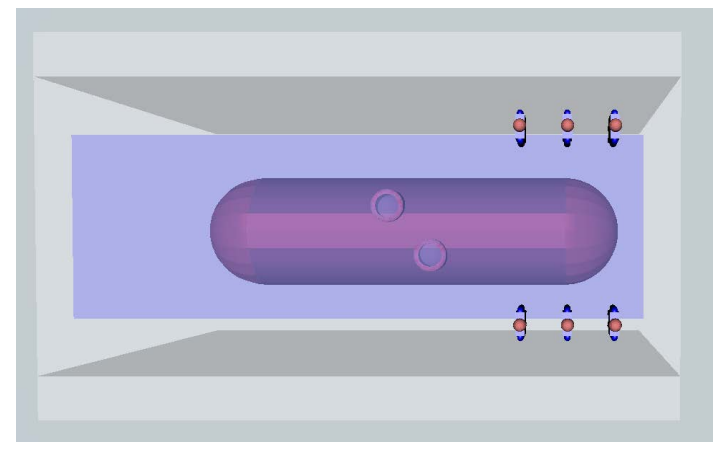

Figure 2. Cutting the end part of steam generator-top view.

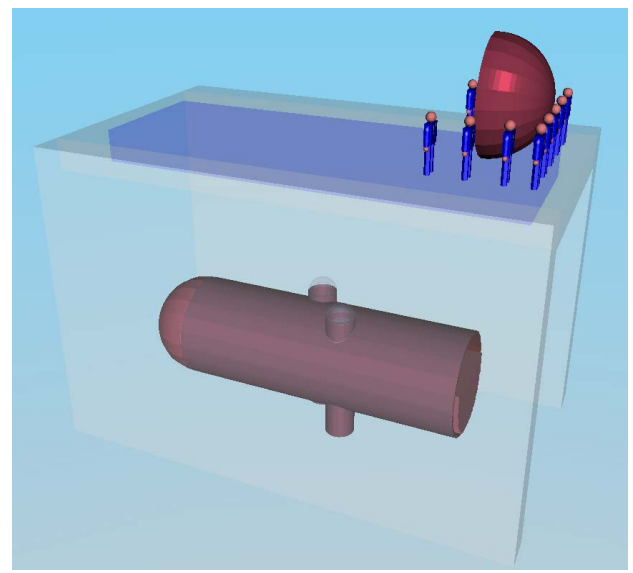

Figure 3. Lifting the fragmented part. 
- Cutting the segment of SG casing and heat exchange tubes-similar situation as depicted in Figure 2. Based on the data from the available technical documentation, the average distance between girders of heat exchange tubes is $68.8 \mathrm{~cm}$, thus the width of the fragments is considered to be $70 \mathrm{~cm}$ (in order to achieve the fixation of heat exchange tubes during and after cutting as well as during lifting). The total workload is 160 man-hours.

- Lifting the fragmented segment-total workload of 7.5 man-hours-Figure 4.

- Tilting the collector to the horizontal position —-workload of 0.25 man-hours for each collector.

- Lifting the collector-workload 0.55 man-hours for each collector. The situation is depicted in Figure 5.

2) Fragmentation activities

- Fragmentation of casing of the segment-based on the fact that the casing of steam generator is considered to be released into the environment, this part is fragmented first (in order to remove the material and to enable enough space for later fragmentation of heat exchange tubes). The total workload for 15 segments is 300 man-hours, the situation is depicted in Figure 6.

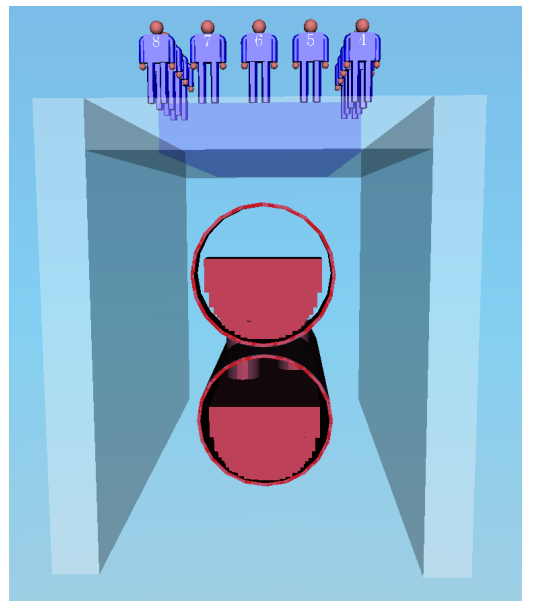

Figure 4. Lifting the fragmented segment—-side view.

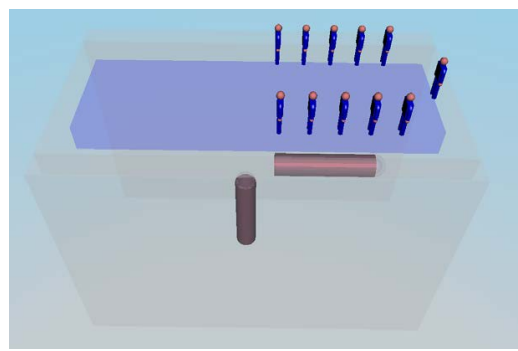

Figure 5. Lifting the collector.

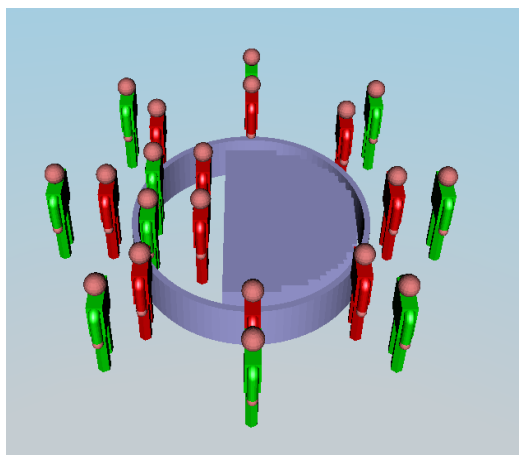

Figure 6. Fragmentation of casing of segment. 
- Fragmentation of heat exchange tubes of the segment-The total workload for 15 segments is 500 man-hours, the situation is depicted in Figure 7.

- Fragmentation of collectors-The total workload is 160 man-hours for each collector-Figure 8.

3) Fragmentation activities

- Fragmentation of casing of the segment-based on the fact that the casing of steam generator is considered to be released into the environment, this part is fragmented first (in order to remove the material and to enable enough space for later fragmentation of heat exchange tubes). The total workload for 15 segments is 300 man-hours, the situation is depicted in Figure 6.

- Fragmentation of heat exchange tubes of the segment-The total workload for 15 segments is 500 manhours, the situation is depicted in Figure 7.

- Fragmentation of collectors-The total workload is 160 man-hours for each collector-Figure 8.

\section{Results}

The results of the calculations are presented in Tables 2-4. As was mentioned in the beginning of the paper, the $2^{\text {nd }}$ decommissioning stage is planned between 2015 and 2025. From this reason, the influence of time on the exposure was studied as well-Table 4. For lucidity, only total results are presented in Table $\mathbf{3}$ and Table 4. The issue of fragmentation of the segments was analyzed more in detail in [9].

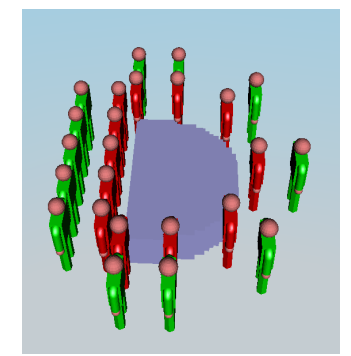

Figure 7. Fragmentation of heat exchange tubes.

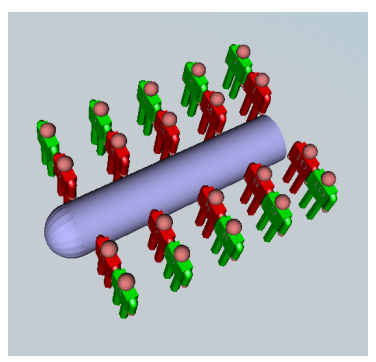

Figure 8. Fragmentation of collector.

Table 2. Remote dismantling of steam generator-total in 2015.

\begin{tabular}{|c|c|c|c|}
\hline Task & $\begin{array}{c}\text { Workload } \\
\text { [manh] }\end{array}$ & $\begin{array}{l}\text { Average dose } \\
\text { rate }[\mathrm{mSv} / \mathrm{h}]\end{array}$ & $\begin{array}{c}\text { Collective effective } \\
\text { dose [manmSv] }\end{array}$ \\
\hline Cutting the end part of steam generator & 35 & $2.52 \mathrm{E}-03$ & $8.80 \mathrm{E}-02$ \\
\hline Lifting the fragmented part & 1 & $4.21 \mathrm{E}-03$ & $4.21 \mathrm{E}-03$ \\
\hline Cutting the segment of SG casing and heat exchange tubes & 160 & $3.57 \mathrm{E}-03$ & $5.72 \mathrm{E}-01$ \\
\hline Lifting the fragmented segment & 7.5 & $1.34 \mathrm{E}-01$ & $1.00 \mathrm{E}+00$ \\
\hline Tilting the collectors to the horizontal position & 0.5 & $5.73 E-05$ & $2.87 \mathrm{E}-05$ \\
\hline Lifting the collectors & 1.1 & $3.94 \mathrm{E}-04$ & $4.34 \mathrm{E}-04$ \\
\hline Total & 205.1 & - & 1.7 \\
\hline
\end{tabular}


Table 3. Fragmentation of the segments-total in 2015.

\begin{tabular}{cccc}
\hline Task & $\begin{array}{c}\text { Workload } \\
{[\mathbf{m a n h}]}\end{array}$ & $\begin{array}{c}\text { Average dose rate } \\
{[\mathbf{m S v} / \mathbf{h}]}\end{array}$ & $\begin{array}{c}\text { Collective effective } \\
\text { dose [manmSv] }\end{array}$ \\
\hline Fragmentation of casing of the segment & 300 & $2.99 \mathrm{E}-01$ & $9.04 \mathrm{E}+01$ \\
Fragmentation of heat exchange tubes of the segment & 500 & $8.84 \mathrm{E}-01$ & $2.23 \mathrm{E}+02$ \\
Fragmentation of collectors & 320 & $1.68 \mathrm{E}-03$ & $5.41 \mathrm{E}-01$ \\
Total & $\mathbf{1 1 2 0}$ & - & $\mathbf{3 1 3 . 9}$ \\
\hline
\end{tabular}

Table 4. The inluence of time-general comparison.

\begin{tabular}{cccc}
\hline \multirow{2}{*}{ Task } & \multicolumn{2}{c}{ Total collective effective dose [manmSv] } \\
\cline { 2 - 4 } & $\mathbf{2 0 1 5}$ & $\mathbf{2 0 2 0}$ & $\mathbf{2 0 2 5}$ \\
\hline Remote dismantling of steam generator & 1.7 & 0.9 & 0.5 \\
Fragmentation of the segments & 313.9 & 164.9 & 88.4 \\
Total & $\mathbf{3 1 5 . 6}$ & $\mathbf{1 6 5 . 8}$ & $\mathbf{8 8 . 9}$ \\
\hline
\end{tabular}

\section{Conclusion}

From the results depicted in Tables 2-4 it can be stated that biggest contribution to the total collective effective dose is from the activities regarding the fragmentation of the segments. This can be expected because these tasks are carried out in the vicinity of the most contaminated part-heat exchange tubes.

The general overview in the Table 4 shows that the time period of 5 years results in approx. 1.9-times decrease of total collective effective dose. This is in accordance with the half-life of ${ }^{60} \mathrm{Co}$ (5.27 a) which is the most dominant nuclide within the considered nuclide vector.

The calculated dose rates and thus the doses are quite high. As was mentioned in Chapter 4.2, no pre-dismantling decontamination is considered. This is, however, a very conservative assumption. Several projects regarding decontamination of the primary circuit of shut-down NPPs with pressurized water reactors were realized, for instance, in German NPP Unterweser (1345 MWe, more than 30 years of operation) where the decontamination factor (DF) of 147 of SG tube section was achieved [10]. When considering the DF of 100, it can be expected that the dose rates will be 2 orders of magnitude lower. This will be probably also the case of NPP V1 in Jaslovské Bohunice, where the decontamination of the primary circuit is realized.

During the creation of calculation models and trajectories the site-specific conditions were taken into account which enables the application of the results in the planning of the dismantling process and fragmentation activities together with their optimization in accordance with the ALARA principle.

\section{Acknowledgements}

This project has been supported by the Slovak Grant Agency for Science through grant VEGA 1/0796/13.

\section{References}

[1] Organisation for Economic Co-Operation and Development-Nuclear Energy Agency. Radioactive Waste Management Committee (2012) The Management of Large Components from Decommissioning to Storage and Disposal: A report of the Task Group on Large Components of the NEA Working Party on Decommissioning and Dismantling (WPDD). NEA/RWM/R(2012)8. Paris: OECD/NEA.

[2] National Nuclear Found for Decommissioning of Nuclear Installations and for Spent Fuel and Radioactive Waste Management (2012) Strategy of Back-end of Peaceful Use of Nuclear Energy in Slovak Republic. (In Slovak)

[3] Nuclear and Decommissioning Company (2013) The Intent in terms of the Act No. 24/2006 Coll. on Environmental Impacts Assessment and Alternations and Amendments of certain Acts as Amended-The 2nd Stage of Decommissiong of V1 NPP Jaslovské Bohunice. (In Slovak) http://www.javys.sk/sk/o-spolocnosti/projekty/posudenie-vplyvu-2-etapy-vyradovania-je-v1-na-zp/dokumenty 
[4] Roupec, P. (2010) Transfer Heat Analysis in Steam Generators in Blocks of VVER 440. Master's thesis, Energy Institute, Faculty of Mechanical Engineering, Brno University of Technology. (In Czech)

[5] International Atomic Energy Agency (1997) Assessment and Management of Ageing of Major Nuclear Power Plant Components Important to Safety: Steam generators. IAEA-TECDOC-981. ISSN 1011-4289, pp. 15-17.

[6] Vermeersch, F. (2005) Dose Assessment and ALARA Calculation with VISIPLAN 3D ALARA Planning Tool, Training Course. IDPBW Nuclear Studies, Boeretang: SCK.CEN, Belgium.

[7] Rohde, M. (2011) Treatment and Conditioning of Dismantled Material and Operation Waste in EWN, Overview. http://www.iaea.org/OurWork/ST/NE/NEFW/WTS-Networks/IDN/idnfiles/CuttingTechniqueWkp-Germany2011/Trea tment-and-Conditioning-of-DismantledMaterial-and-OperationWaste.pdf

[8] Personal and via E-Mail Consultation with Mr. Andreas Hammel from the Company WIKUS within the Seminar “Fachtagung Rückbau-Fachtagung zur Technik und Praxis des Rückbaus von Kernkraftwerken” organised by Kraftwerksschule e.v. in NPP Zwentendorf, Austria, from 24-25 September 2014.

[9] Hornacek, M. and Necas, V. (2015) The Assessment of NPP V1 Steam Generator Dismantling from the Perspective of External Exposure. Proceedings of International Conference ECED 2015-Eastern and Central European Decommissioning, 23-25 June 2015, Trnava, Slovakia.

[10] Topf, Ch., Belda, L.S., Fischer, M., Tscheschlok, K. and Volkmann, Ch. (2013) Full System Decontamination at German Nuclear Power Plant Unterweser. International Journal for Nuclear Power, 58, 216-220. 